\title{
Pembinaan Pengetahuan Moral Pancasila Siswa Sekolah Dasar melalui Model Scaffolding Writing
}

\author{
Yana Nuryana1, Riva Ayuningtyas, Rokhmatun Nabillah, Asep Dahliyana \\ 1yananuryana@student.upi.edu \\ Universitas Pendidikan Indonesia
}

$\begin{array}{ccc}\text { Disubmit } & \text { Direvisi } & \text { Diterima } \\ \text { 18 Agustus 2018 } & \text { 21 November 2018 } & \text { 28 Desember 2018 } \\ & \text { http://dx.doi.org/10.17509/jpis.v27i2.12529 } & \end{array}$

\begin{abstract}
This study aims to improve 21st-century life skills for elementary school students based on Pancasila through scaffolding writing model. The scaffolding writing model is a multi literacy learning which consists of the following stages. (1) pre-writing; (2) writing; and (3) post writing. This study uses a quantitative approach with the preexperimental method of one group pretest-posttest design. The results of this study indicate that the application of scaffolding writing model is effective to improve students' moral knowledge of Pancasila by 1.08 (difference between pretest and posttest results). The increasing of students' moral knowledge can be seen when the students write examples and classify activities related to Pancasila, provide reasons for activities that have been classified, and make plans for activities to be carried out
\end{abstract}

Keywords: pancasila moral knowledge, models of scaffolding, diary-based.

\begin{abstract}
ABSTRAK
Penelitian ini bertujuan untuk meningkatkan keterampilan kehidupan abad 21 pada siswa sekolah dasar yang berlandaskan Pancasila melalui model scaffolding writing. Model scaffolding writing merupakan pembelajaran multiliterasi yang terdiri dari tahapan berikut: (1) pra-menulis; (2) menulis; dan (3) pasca menulis. Penelitian ini menggunakan pendekatan kuantitatif dengan metode pra eksperimen desain one group pretest posttest. Hasil penelitian ini menunjukkan bahwa penerapan model scaffolding writing mampu meningkatkan pengetahuan moral Pancasila siswa sebesar 1,08 (selisih hasil pretest dan posttest). Peningkatan pengetahuan moral siswa dapat dilihat pada saat siswa menuliskan contoh dan mengklasifikasikan kegiatan yang berhubungan dengan Pancasila, memberikan alasan dari kegiatan yang sudah digolongkan, dan membuat rencana kegiatan yang akan dilakukan.
\end{abstract}

Keywords: Pengetahuan Moral Pancasila, Model Scaffolding Writing, Diari Terbimbing.

\section{PENDAHULUAN}

Pendidikan Nasional Indonesia bertujuan untuk mengembangkan siswa menjadi manusia yang bermoral, yakni beriman dan bertakwa kepada Tuhan Yang Maha Esa, berakhlak mulia, mandiri, waga negara yang demokratis, dan bertanggung jawab (Pasal 3 UU SISIDIKNAS No. 20 tahun 2003). Akan tetapi, pendidikan nasional belum mampu mencerahkan bangsa ini (Muslich, 2013: 1-2). Pendidikan yang diselenggarakan terutama di sekolah dasar belum dilaksanakan secara 
optimal, sehingga pembelajaran dirasakan kurang bermakna dan terjadi kesenjangan antara pengetahuan moral dan perilaku siswa (Megawangi, 2004: 80). Hal tersebut mengakibatkan siswa memperlihatkan karakter-karakter negatif, seperti mencuri, menipu, berbohong, berkata kotor dan kasar, merusak milik sekolah, membolos, mengganggu teman atau orang lain dengan menggertak, mengejek, menimbulkan keributan, perkelahian, perundungan, dan bentuk-bentuk kenakalan remaja lainnya (Giyono dan Sentono, 2017; Noor, 2014: Samani dan Hariyanto, 2011: 2).

Keadaan tersebut karena telah terjadi disorientasi dan belum dihayatinya nilai-nilai Pancasila, keterbatasan perangkat kebijakan terpadu dalam mewujudkan nilai-nilai Pancasila, bergesernya nilai etika dalam kehidupan berbangsa dan bernegara, memudarnya kesadaran terhadap nilainilai budaya bangsa, dan melemahnya kemandirian bangsa (Kemdiknas, 2010:8-9). Keaadaan ini menambah kekhawatiran guru maupun praktisi pendidikan, terlebih dalam menghadapi kehidupan abad 21, di mana pendidikan harus memberikan keterampilan seperti, (1) sikap kewarganegaraan, baik dalam lingkup lokal maupun global; (2) berkehidupan dan berkarier; dan (3) responsibilitas personal dan sosial (Binkleey, et al. dalam Abidin, 2015: 101).

Oleh sebab itu, diperlukan suatu cara agar pendidikan dapat memperlihatkan tajinya dalam peran serta melahirkan generasi holistik, salah satunya yaitu dengan cara membina nilai-nilai Pancasila sebagai jati diri bangsa agar pribadi penerus bangsa tidak mudah goyah oleh derasnya arus globalisasi (Dahliyana, 2017; Chairiyah, 2014). Adapun salah satu cara yang dilakukan untuk mengatasi permasalahan di atas, yaitu dengan menanamkan dan memberikan pengetahuan moral Pancasila sejak dini (Muslich, 2013: 1). Hal tersebut dapat dipahami, sebab apabila karakterkarakter yang ditanamkan sejak kecil akan melekat pada proses pendewasaan selanjutnya (Sulthoni, 2016: 106).

Berbagai hasil penelitian menjelaskan bahwa cara untuk penanaman nilai-nilai Pancasila dapat dilakukan melalui upaya pembiasaan, pengamalan, pengkondisian lingkungan, dan keteladanan (Sutjipto, 2014: 483). Pandangan lain menyebutkan bahwa penanaman nilainilai Pancaila dapat dilakukan dengan metode inkulkasi (inculcation), keteladanan (modeling), fasilitasi (facilitation), dan pengembangan keterampilan (skill building) (Mustaqim, 2015: 169). Dalam arikel ini, penanaman nilai-nilai Pancasila diberikan melalui pengembangan keterampilan, di mana siswa dilibatkan secara aktif dalam proses pembelajaran dengan tujuan agar secara mandiri menemukan jawaban dari masalah yang dihadapi (Susanto, 2016: 8).

Adapun model pembelajaran yang dikembangkan dalam penanaman pengetahuan moral Pancasila, yaitu model scaffolding writing. Scaffolding writing merupakan model pembelajaran menulis di mana kerangka penulisannya ditentukan oleh guru (Abidin, 2015: 203). Model tersebut dapat memberikan bimbingan secara penuh kepada siswa pada saat proses pembelajaran, karena dalam penerapannya sangat memperhatikan prosedur pembelajaran menulis, seperti pola tulis, pola pikir, dan pola kontrol (Supendi, dkk., 2017: 445) sebagai contextualizing karena guru membuat 
analogi dari tujuan teks deskriptif berdasarkan dunia siswa (Walqui, 2006: 173). Oleh sebab, teks yang diberikan guru kepada siswa dapat memberikan gambaran seperti apa produk tulisan yang akan siswa buat (Gibbons, 2002: Walqui, 2006) dan dapat meningkatkan keaktifan siswa dalam menulis (Kasmaini, 2010: 1) Hal tersebut dapat menambah ketertarikan siswa terhadap tugas dan mengendalikan frustasi siswa selama mengerjakan tugas (Wood, Bruner, dan Ross, 1976: 98)

Selama ini, penggunaan model scaffolding writing hanya berfokus untuk melatih keterampilan menulis siswa saja tanpa disertai sikap atau karakter yang ingin dikembangkan. Selain itu, penelitian-penelitian yang dilakukan masih terfokus terfokus untuk bahasa dan matematika (Kasmaini, 2010: Bakker, et.al, 2015: Laksmi, 2006: Wilson and Devereux, 2014; Yuanying, 2011: 46) dan belum terdapat penelitian yang memfokuskan dengan Pendidikan Pancasila dan Kewarganegaraan. Dengan demikian, tim sangat tertarik untuk meneliti pengaruh model scaffolding writing terhadap pembinaan pengetahuan moral Pancasila siswa sekolah dasar.

\section{METODE PENELITIAN}

Penelitian dilaksanakan selama kurang lebih satu bulan dari April - Mei 2018. Metode penelitian yang digunakan, yaitu metode praeksperimen dengan desain one group pretest posttest yang memiliki tiga langkah, (1) tes awal sebelum memperoleh treatment (pretest); (2) tindakan (treatment); dan (3) tes akhir setelah memperoleh treatment (posttest) (Sukmadinata, 2015: 208).
Adapun gambar dari desain penelitian yang dilakukan, yaitu sebagai berikut.

Kelompok Pretest Treatment Postest

$$
\mathrm{A} \rightarrow \mathrm{O}_{1} \rightarrow \mathrm{X} \rightarrow \mathrm{O}_{2}
$$

Gambar 1. Desain Penelitian One Group Pretest Posttest

Keterangan:

$\mathrm{O} 1=$ Nilai pretest

$\mathrm{X} \quad=$ Perlakuan atau tindakan yang diberikan (variabel independen)

$\mathrm{O}_{2}=$ Nilai posttest

Populasi yang terlibat dalam penelitian yaitu siswa kelas IV semester genap yang telah dipilih saat awal observasi dengan berjumlah 29 siswa. Adapun teknik yang digunakan dalam pengambilan sampel, yaitu menggunakan teknik sampling purposive di mana dalam pengambilan sampel peneliti menggunakan syarat harus mengikuti pretest dan postest. Sehingga diperoleh sampel dalam penelitian ini, yaitu sebanyak 19 siswa. Instrumen penelitian yang digunakan peneliti terdiri dari dua jenis, yaitu instrumen treatment dengan diari terbimbing dan instrument pengumpulan data berupa tes yang mengukur aspek kesadaran moral, penalaran moral, dan pengambilan keputusan (Lickona, 2013: 85-100).

Pengolahan data instrumen pretest dan posttest, dilakukan melalui penilaian berbentuk skoring dengan memakai rating scale skala 0-4 yang dapat digambarkan dalam tabel 1.

Selanjutnya, berdasarkan hasil pretest yang telah dikerjakan, peneliti membagi pengetahuan moral Pancasila siswa ke dalam lima kelompok, yaitu kelompok sangat kurang, kurang, cukup, baik, dan sangat baik. Adapun norma yang dipakai berdasarkan hasil pretest siswa dapat dilihat pada tabel 2 . 
Tabel 1. Scoring Data Pretest dan Postest

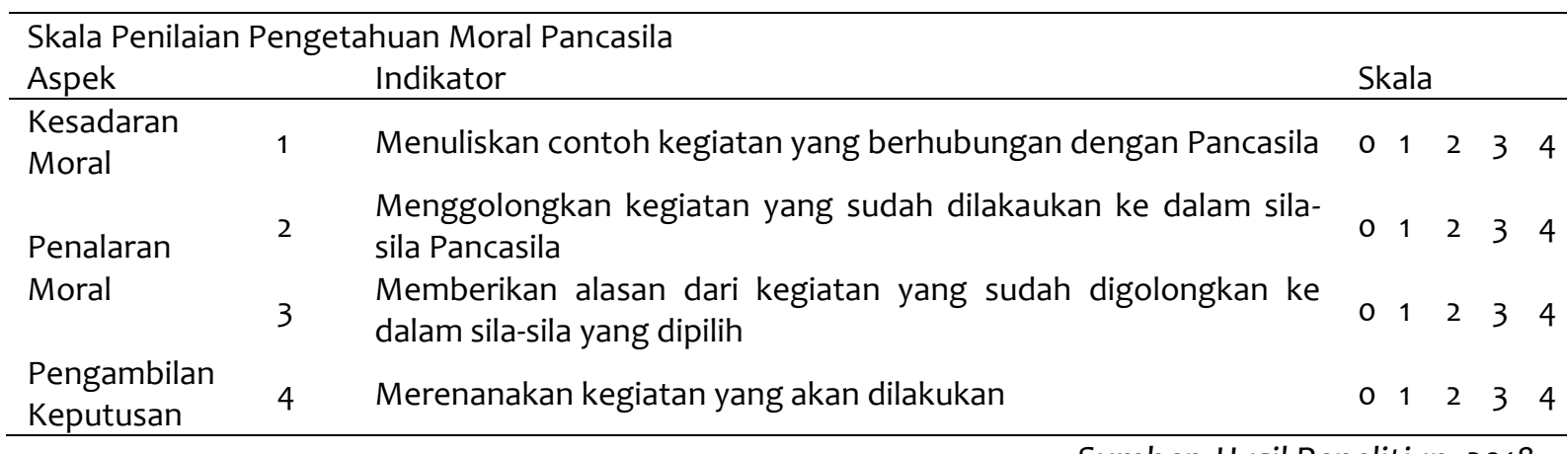

Sumber: Hasil Penelitian, 2018

Tabel 2. Norma Pengelompokkan

Pengetahuan Moral Pancasila Siswa

\begin{tabular}{cc}
\hline Rentang Rerata & Kriteria \\
\hline$\leq 0,75$ & Sangat Kurang \\
$0,75<x \leq 1,5$ & Kurang \\
$1,5<x \leq 2,0$ & Cukup \\
$2<x<2,5$ & Baik \\
$\geq 2,5$ & Sangat Baik \\
\hline \multicolumn{2}{r}{ Sumber: Hasil Penelitian, 2018 }
\end{tabular}

Analisis data dilakukan terhadap data pretest dan data postest, meliputi uji validitas dan reliabilitas instrumen, uji normalitas, dan uji perbedaan rerata. Pengujian tersebut bertujuan untuk mengetahui perbedaan rerata antara hasil pretest dan posttest yang pengujiannya dipermudah dengan menggunakan software SPSS versi 21. Hasil pengambilan keputusan valid tidaknya suatu instrumen ditentukan oleh nilai signifikansi dari setiap item, yaitu (1) jika nilai signifikansi item $>0.05$ maka item dinyatakan valid; dan (2) jika nilai signifikansi item < 0.05 maka item dinyatakan tidak valid. Melalui program SPSS versi 21., didapatkan nilai validitas untuk setiap item soal, yaitu 0.551 , $0.769,0.808$, dan 0.646 yang mana ke empat nilai tersebut $>0.05$, sehingga semua item soal dapat dinyatakan valid.

Berdasarkan hasil dari uji reliabilitas, didapatkan nilai reliabilitas sebesar 0.625 sehingga tingkat reliabilitas penelitian ini dapat diklasifikasikan ke dalam kriteria tinggi. Adapun uji normalitas data dilakukan untuk mengetahui apakah data yang dihasilkan berdistribusi normal atau tidak. Dasar pengambilan keputusan dalam uji normalitas data, yaitu jika nilai signifikansi lebih besar dari 0,05 maka data tersebut berdistribusi normal, sedangkan jika nilai signifikansi lebih kecil dari 0,05 maka data tersebut tidak berdistribusi normal. Dari hasil uji normalitas dengan bantuan SPSS versi 21., didapatkan nilai signifikansi 0.200 (kolmogorof-smirnov) dan 0.620 (shapiro-wilk) sehingga dapat dinyatakan bahwa data kelompok tersebut berdistribusi normal.

Untuk mengetahui kualitas peningkatan pengetahuan moral Pancasila dengan diterapkannya model scaffolded writing berbasis diari terbimbing, maka dilakukan uji gain ternormalisasi. Dengan rumus berikut.

$$
\text { Indeks Gain }=\frac{\text { Spostes }- \text { Spretes }}{\text { Smaksimum }- \text { Spretes }}
$$

Dalam penentuan kategori kualitas pengaruh suatu tindakan, peneliti menggunakan interpretasi indeks gain ternormalisasi menurut Hake (Latief, $\mathrm{H}$. dkk, 2014) yang sudah dimodifikasi, yaitu high $(0.7<\mathrm{g}<1)$, average $(0.3<\mathrm{g}<$ $0.7)$, low $(0.0<\mathrm{g}<0.3)$, stable $(\mathrm{g}=0.0)$, dan decrease $(-1.00<\mathrm{g}<0.0)$. 


\section{HASIL DAN PEMBAHASAN \\ Data Pretest}

Pelaksanaan pretest dilakukan pada tanggal 27 April 2018 dengan waktu 45 menit. Adapun hasil penghitungan pretest mengenai pengetahuan moral Pancasila, yaitu sebagai berikut.

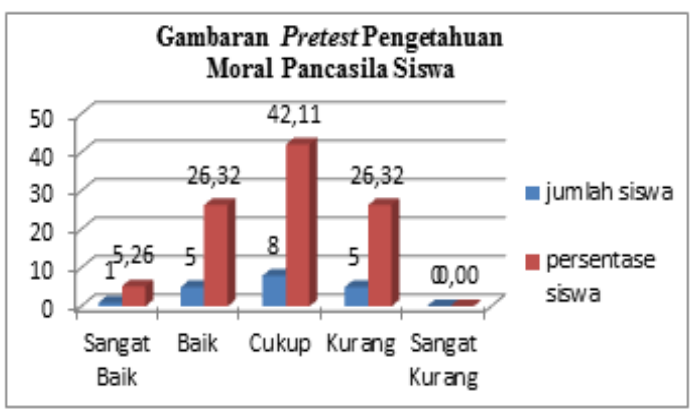

Gambar 2. Gambaran Pretest

Pengetahuan Moral Pancasila Siswa

Dari gambar 2. di atas, diketahui bahwa sebagian besar siswa berada dalam kriteria cukup dalam memahami pengetahuan moral Pancasila dengan jumlah siswa 8 orang atau 42,11\%.

\section{Data Posttest}

Pelaksanaan posttest dilakukan pada tanggal 25 Mei 2018 dengan waktu 45 menit dengan teknis pengerjaan sama seperti pembagian soal pretest. Soal posttest diberikan kepada siswa setelah mereka mendapat tretament berupa penerapan model scaffolding writing berbasis diari terbimbing selama satu minggu ( $16-22$ Mei 2018). Berikut hasil penghitungan soal posttest siswa kelas IV.

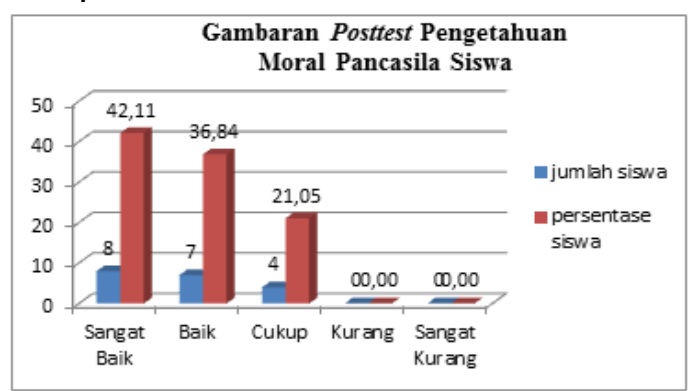

Gambar 3. Gambaran Posttest

Pengetahuan Moral Pancasila Siswa
Dari tabel di atas, diketahui bahwa sebagian besar siswa setelah mendapatkan tindakan berupa penerapan model scaffolding writing berbasis diari terbimbing berada dalam kriteria sangat baik dalam memahami moral Pancasila, dengan jumlah 8 orang atau $42,11 \%$.

\section{Hasil Penerapan Model Scaffolded} writing Berbasis Diari Terbimbing terhadap Pengetahuan Moral Pancasila

Adapun perbandingan hasil pengetahuan moral siswa sebelum dan setelah penerapan model scaffolding writing berbasis diari terbimbing dapat dilihat pada gambar berikut.

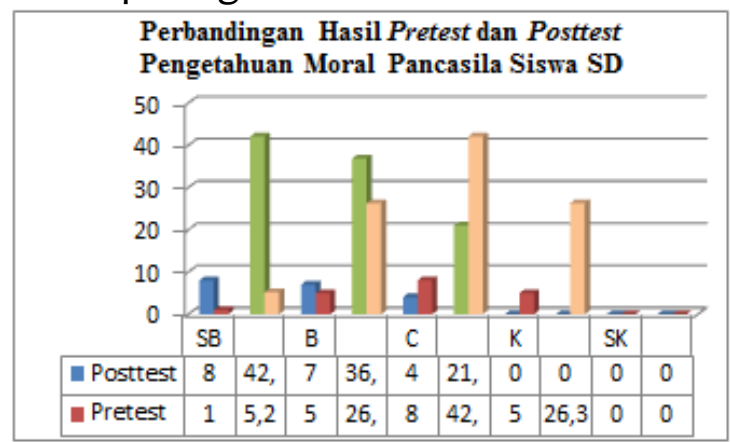

Gambar 4. Perbandingan Hasil Pretest dan Posttest Pengetahuan Moral Pancasila Siswa SD

Pada gambar 4 dapat dilihat bahwa peningkatan pengetahuan moral siswa sangat signifikan, dimana sebagian besar siswa dalam kelas tersebut telah berada dalam kategori tinggi, yaitu 8 orang atau $42.1 \%$ dan tidak ada siswa yang berada dalam kategori kurang atau sangat kurang. Selain itu, pengetahuan moral Pancasila mengalami peningkatan dalam semua indikator setelah diterapkannya model scaffolding writing berbasis diari terbimbing. Berikut hasil analisis peningkatan setiap indikator pengetahuan moral Pancasila. 


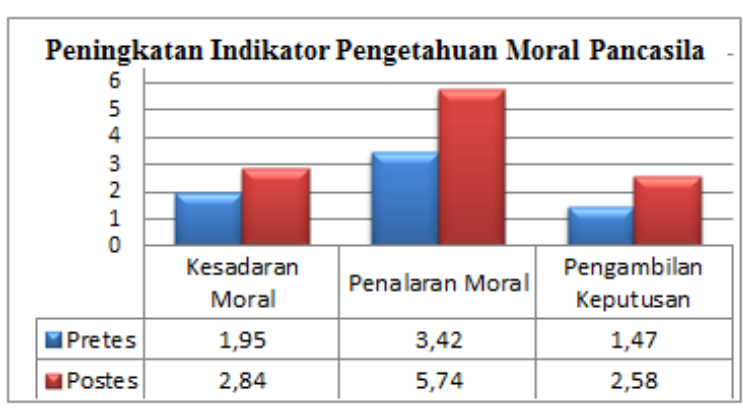

Gambar 5. Peningkatan Indikator Pengetahuan Moral Pancasila

Pada gambar di atas, terlihat bahwa semua indikator pengetahuan moral mengalami peningktan. Peningkatan yang mempunyai selisih paling besar terdapat dalam komponen penalaran molar, dimana didalamnya mempunyai dua indikator, yaitu menggolongkan kegiatan hariannya ke dalam sila-sila Pancasila dan memberikan alasan mengenai penggolongan yang sudah dilakukannya.

\section{Pembahasan}

Berdasarkan hasil observasi peneliti sebelum dilaksanakan treatment, beberapa siswa selalu bertengkar di luar batas wajar. Seperti memukul temannya menggunakan benda di sekitar kelas, melukai temannya dengan cara memukul, menonjok ataupun menendang, saling memaki, saling mengejek, terkadang tidak mau dikelompokkan, menyanyikan lagu kebangsaan dengan bermain-main, dan belum ada percakapan antara temannya untuk saling mengingatkan. Hal tersebut mengindikasikan kurangnya pemahaman dan pelaksanaan moral Pancasila dalam kehidupan siswa (Muslich, 2013: Kemdiknas, 2010). Perubahan perilaku kurang baik siswa tersebut, merupakan suatu hal yang harus diberi perhatian dan dicari solusinya agar penerus bangsa tidak mudah goyah oleh derasnya arus globalisasi (Chairiyah,
2014: 61). Salah satu cara yang dapat ditempuh, yaitu dengan mengajarkan pendidikan karakter yang termuat di dalam materi mata pelajaran yang dimulai dari pengetahuan moral dan berdampak secara tidak langsung pada tindakan moral (Lickona, 2013: 89).

Instrumen yang digunakan untuk mengetahui pengetahuan moral Pancasila siswa yaitu menggunakan tes yang memuat tiga aspek pengetahuan moral, yaitu kesadaran moral, penalaran moral, dan pengambilan keputusan.. Setelah diadakan tes, diketahui bahwa sebagian besar siswa masih berada dalam kategori cukup, yaitu $42,11 \%$ yang mana masih harus dioptimalkan. Sehingga, peneliti mengungkapkan bahwa ada hubungan antara pengetahuan dengan sikap sesuai ungkapan Fakhri (2016: 65) bahwa keterkaitan antara nilai, moral, sikap, dan tingkah laku akan tampak dalam pengamalan nilai-nilai yang dimulai dari mengetahui nilai-nilainya terlebih dahulu dalam hal ini nilai-nilai Pancasila.

Setelah diadakan treatment berupa penerapan model scaffolding writing berbasis diari terbimbing selama 6 hari, pengetahuan moral Pancasila mengalami peningkatan baik dari setiap aspek maupun setiap siswa. Seluruh siswa antusias dalam mengikuti pembelajaran yang dirancang oleh guru, karena guru selalu menawarkan berbagai permainan yang menstimulus siswa untuk berperan aktif dalam proses menulis diari maupun refleksi. Sebagai informasi, bahwa secara umum Scaffolding terdiri dari berbagai jenis yaitu: (1) modeling; (2) offering explanation; (3) bridging; (4) contextualizing; (5) schema building; (6) inviting students' participation; (7) verifying and clarifying students' understanding; dan (8) developing 
metacognition, (Gibbons, 2002; Walqui, 2006; Lange, 2002)

Beberapa faktor yang menyebabkan adanya peningkatan pengetahuan moral Pancasila siswa, diantaranya sebagai berikut.

\section{Pengembangan Konsep Literasi}

Konsep literasi yang dikembangkan dalam penelitian ini disesuaikan dengan tingkat literasi siswa kelas IV yang secara otomoatis membaca dan memahami beragam genre teks termasuk biografi dengan topik yang berbeda, teks fantasi, buku misteri, diari, mitos, dan legenda (Abidin, dkk., 2015: 280). Teks literasi yang dikembangkan dalam penelitian ini berupa diari, sehingga pada saat peneliti meminta siswa untuk menuliskan diari ini tidak menjadi tantangan yang memberatkan oleh siswa. Dengan demikian, jenis scaffolding writing yang dikembangkan yaitu contextualizing bertujuan untuk membawa ide-ide kompleks dari topik yang akan diajarkan menjadi lebih dekat dengan dunia pengalaman siswa (Walqui, 2006: 173). Selain itu, membaca dan menulis secara psikologis dapat memberikan keterampilan kognitif individu, sehingga perlu ditingkatkan pada pemahaman literasi yang lebih dalam sebagai praktik sosial (Luke \& Freebody, 1997: 185). Adapun dalam penelitian ini penulis mengeksplorasi ide-ide atau gagasan yang akan ditulis agar dapat memberikan pengetahuan awal (prior knowledge) sesuai dengan topik tulisannya (Meyers, 2005, hlm. 3).

Konsep Menulis sebagai Media Ekspresi dan Media Membangun Makna

Siswa yang secara langsung menganalisis pengalaman hariannya dan menghubungkan dengan nilai-nilai
Pancasila, membuat kebermaknaan yang tertanam dalam diri siswa dan rasa bangga pada saat diskusi secara bersama-sama terhadap aya yang telah dianalisisnya. Setalah semua menyepakati berbagai pendapat bahwa kegiatan hariannya benar dalam pemaknaan Pancasila, maka siswa lebih merasa yakin akan pengetahuannya dan cenderung mengingat hal tersebut.

Hal tersebut disebabkan menulis memiliki tujuan artistik (nilai keindahan), tujuan informatif, yaitu memberi informasi kepada pembaca dan tujuan persuasif yakni mendorong atau menarik perhatian pembaca agar mau menerima informasi yang disampaikan oleh penulis (Supriyadi, 1994: 225). Oleh karena itu, kemampuan menulis seseorang perlu dilatih sejak dini (Akhadiah, 1992: 104).

Untuk mampu menulis pada usia dini, anak perlu diberi pajangan berupa teks-teks bacaan yang diharapkan akan menjadi inspirasi bagi anak untuk mengembangkan kemampuan menulisnya pada tahap awal (Budiyanto, 2005: 149). Benninga menyatakan bahwa karakter dapat dikembangkan melalui kegiatan menulis (2003: 30). Oleh sebab, dalam kegiatan gerakan literasi terdapat kegiatan mencatat, yang menurut Lehaoux merupakan esensi dari deskripsi gerakan tersebut (2013: 154).

\section{Pengaruh Faktor Internal}

Faktor internal merupakan faktor yang berasal dari dalam diri individu yang sedang mengalami proses pembelajaran dan berkembang. IQ siswa memang sangat berpegaruh dalam penelitian ini, karena semakin tinggi IQ siswa maka proses analisis kegiatan harian terhadap pengetahuan moral Pancasila akan lebih mudah dipahami. Lalu, kepribadian siswa yang 
senang terhadap hal baru menjadikan menulis kegiatan harian sekaligus menganalisisnya merupakan sesuatu yang menyenangkan (Wahyono, 2017: 267).

\section{Pengaruh Faktor Eksternal}

Faktor eksternal adalah faktor yang berasal dari luar individu. Pengaruh guru dan orang tua sangatlah berperan dalam penelitian ini. Guru kelas yang mengarahkan siswa untuk selalu menyangkutpautkan kegiatannya dengan moral Pancasila memfasilitasi siswa untuk mendapatkan pengembangan dari hal-hal baru yang ditemuinya bersama guru kelas.

Peningkatan yang terjadi pada siswa bukan hanya dari segi pengetahuan, tapi sikap yang ditunjukkan dalam kehidupan sehari-harinya pun ikut meningkat ke arah yang lebih baik. Siswa yang sering bertengkar sudah mulai jarang bertengkar, bahkan siswa yang bertengkar dengan menggunakan benda-benda di sekitar kelas terlihat sudah tidak melakukan hal tersebut lagi. Siswa yang sering bertengkar lebih mampu mengontrol emosi karena banyaknya teman yang ikut mengingatkan dan menenangkan siswa tersebut. Banyak siswa yang sudah mulai menghayati sampai meneteskan air mata saat menyanyikan lagu nasional, dan selalu menempatkan tangannya di dadanya saat menyanyikan lagu kebangsaan dengan posisi tubuh yang tegap dan khidmat. Siswa selalu mau dikelompokkan dengan siapapun bahkan mau bermain dengan adik kelas dan kakak kelas dan semua siswa selalu mengingatkan mengenai perilaku mereka sehari-hari khususnya dalam pelaksaan Pancasila kesatu, yaitu melaksanakan ibadah sesuai ajaran dan kepercayaannya, mereka saling mengingatkan secara langsung maupun tidak langsung dalam sosial media yang sudah dibuat bersama peneliti.

\section{SIMPULAN}

Berdasarkan temuan, analisis data, dan pembahasan yang sudah dipaparkan, model scaffolded writing berbasis diari terbimbing mampu meningkatkan pengetahuan moral Pancasila dengan kualitas peningkatan dalam kategori sedang. Adapun kelebihan yang terdapat dalam model scaffolding writing berbasis diari terbimbing, yaitu penerapan pembelajaran multiliterasi yang menjadi salah satu unsur dalam pendidikan abad 21.

\section{REKOMENDASI}

Pembinaan moral Pancasila melalui model Scaffolding Writing telah terbukti berdampak secara signifikan terhadap pembentukan karakter positif pada siswa SD. Hal tersebut memberikan gambaran bahwa peningkatan pengetahuan moral berbanding lurus dengan tindakan moral siswa yang tampak dalam kehidupan sehari-hari di sekolah. Sebagai tindak lanjut dari penelitian ini, perlu dilakukan juga penelitian untuk mengembangkan proses pembelajaran yang dapat meningkatkan karakter positif pada siswa SMP dan SMA.

\section{DAFTAR PUSTAKA}

Abidin, Y. (2015). Pembelajaran Berbasis Pendidikan Karakter. Bandung: Reflika Aditama.

Abidin, Y. (2015). Pembelajaran Multiliterasi. Bandung: Reflika Aditama.

Akhadiah, dkk. (1992). Bahasa Indonesia I. Jakarta: Depdikbud. 
Bakker, A., Smith, J., Wegerif, R. (2015). "Scaffolding and Dalogic Teaching in Mathematics Education; Introduction and Review". ZDM Mathematics Edcation. 47, 1047-1065.

Benninga, J.S. et.al. (2003). "The Relationship of Character Education Implementation an Academic Achievement in Elementary School". Journal of Research in Character Education. 1 (1), 19-32.

Budiyanto, D. (2005). “Mengoptimalkan Kemampuan Menulis Anak Melalui Rangsangan Membaca Sejak Dini" dalam Wiedarti, Pangesti. Menuju BudayaMenulis: Suatu Bunga Rampai. Yogyakarta: Tiara Wacana.

Chairiyah. (2014). Revitalisasi Nilai-Nilai Pancasila sebagai Pendidikan Karakter. TRIHAYU: Jurnal Pendidikan Ke-SD-an. 1 (1), 54-62.

Dahliyana, A. (2017). Penguatan Pendidikan Karakter Melalui Kegiatan Ekstrakurikuler di Sekolah. Jurnal Sosioreligi. 15 (1): 54-64.

Fakhri, M. (2016). Penanaman Nilai-Nilai Moral Siswa Sekolah Dasar. Jurnal Ilmiah Mahasiswa Prodi PGSD FKIP Unsyiah. 1 (1): 68-77.

Gibbons, P. (2002). Scaffolding Language, Scaffolding Learning: Teaching Second Language Learners in the Mainstream Classroom. Portsmouth: Heinemann.
Giyono, W., dan Sentono, T. (2017). Pelaksanaan Pendidikan Moral di Sekolah Dasar Kota Yogyakarta. Jurnal Penelitian. 10 (2): 6-12.

Kasmaini. (2010). The Implementation of Scaffolding in Improving Students Activeness in Writing. Jurnal Kependidikan Triadik. 13 (1), 1-18.

Kemdiknas. (2010). Buku Induk Pembangunan Karakter: Jakarta: Kemendiknas.

Laksmi, E.D. (2006). "Scaffolding" Students' writing in ELF Class: Implementing ProcessApproach". TEFLIN Journal. 17 (2), 144-156.

Lange, V. L. (2002). Instructional Scaffolding. New York: City College of New York

Latief, H., Rohmat D., dan Ningrum, E. (2014). Pengaruh Pembelajaran Kontekstual Terhadap Hasil Belajar. Jurnal Pendidikan Geografi. 14 (1): 11-27.

Lickona, T. (2013). Educating for Character: How Our School Can Teach Respect and Responsibility. Jakarta: Bumi Asksara.

Luke, C. (1997). Media literacy and cultural studies. In S. Muspratt, A. Luke, \& P. Freebody (Eds.), Constructing Critical Literacies: Teaching \& Learning Textual Practice (19-49). Cresskill, NJ: Hampton Press, Inc.

Megawangi, R. (2004). Pendidikan Karakter. Jakarta: Indonesia Heritage Foundation. 
Meyers, A. (2005). Gateways to Academic Writing: Effective Sentences, Paragraphs, dan Essays. New York: Longman.

Muslich, M. (2013). Pendidikan Karakter Menjawab Tantangan Krisis Multidimensional. Jakarta: PT Bumi Aksara.

Mustaqim, M. (2015). Model Pendidikan Karakter Terintegrasi pada Pembelajaran di Pendidikan Dasar. Elementary. 3 (1), 156-170.

Noor, I. H.M. (2014). Reduksi Nilai Moral, Budaya, dan Agama terhadap Implementasi Pendidikan Karakter di Sekolah. Jurnal Ilmiah VISI P2TK PAUDNI. 9 (2), 148-157.

Samani, M dan Hariyanto. (2011). Konsep dan Model Pendidikan Karakter. Bandung: PT Remaja Rosdakarya.

Sukmadinata, N. S. (2015). Pendidikan Penelitian. Bandung: Rosda Karya.

Sulthoni. (2016). Penanaman Nilai-Nilai Budi Pekerti di Sekolah Dasar. Jurnal Pendidikan. 25 (2): 100108.

Supendi, M.R., Syahruddin, D., dan Muliasari, D.N. (2017). Penerapan Scaffolding Writing untuk Meningkatkan Kemampuan Siswa dalam Menulis Karangan Narasi. Jurnal Antologi UPI. 5 (1): 442-450.
Supriyadi, D. (1994). Kreativitas, Kebudayaan dan Perkembangan Iptek. Bandung: Alfabeta.

Susanto, A. (2016). Teori Belajar dan Pembelajaran di Sekolah Dasar. Jakarta: Kencana Prenada Media Group.

Sutjipto. (2014). Pendidikan Budi Pekerti pada Kurikulum Sekolah Dasar. Jurnal Pendidikan dan Kebudayaan. 20 (4), 483-498.

Wahyono, I. (2017). Implementasi NilaiNilai Pancasila dalam Kegiatan Pembelajaran di SDN 1 Sekarsuli. Skripsi. Yogyakarta: Universitas Negeri Yogyakarta

Walqui, A. (2006). Scaffolding Instruction for English Language Learners: A Conceptual Framework. The International Journal of Bilingual Education and Bilingualism, 9 (2), 159-180.

Wilson, K., Devereux, L. (2014). Scaffolding Theory: High Challenge, High Support in Academic Language and Learning (ALL) Contexts. Journal of Academic Language \& Learning. 8 (3), 91-100.

Wood, D., Bruner, J. S., dan Ross G. (1976). The Role of Tutoring in Problem Solving. Journal of Child Psycology and Psychiatry. 17 (2), 89-100.

Yuanying, W. (2011). College English Writing on Scaffolding Theory. Studies in Literature and Language. 3 (3), 46-48. 